\title{
Fabrication and Development of Pectin Microsphere of Metformin Hydrochloride
}

\author{
Pritam Banerjee, ${ }^{1}$ Jyotirmoy Deb, ${ }^{2}$ Amitava Roy, ${ }^{1}$ \\ Amitava Ghosh, ${ }^{2}$ and Prithviraj Chakraborty ${ }^{2}$ \\ ${ }^{1}$ Department of Pharmacy, Himalayan Pharmacy Institute, Majhitar, Rangpo, East Sikkim 737136, India
${ }^{2}$ Bengal College of Pharmaceutical Sciences and Research, Bidhannagar, West Bengal, Durgapur 713212, India
}

Correspondence should be addressed to Jyotirmoy Deb, jyotirmoydev@gmail.com

Received 27 March 2012; Accepted 6 June 2012

Academic Editors: J.-J. Chen, J.-M. Huang, and E. Lattmann

Copyright (C) 2012 Pritam Banerjee et al. This is an open access article distributed under the Creative Commons Attribution License, which permits unrestricted use, distribution, and reproduction in any medium, provided the original work is properly cited.

\begin{abstract}
Purpose. The objective of the proposed work is to evaluate the efficacy of Pectins to qualify them as polymers for designing an oral microsphere for the delivery of selected oral antidiabetic drug-like metformin hydrochloride. Methods. Different Microspheres formulations were prepared by the water in oil $(\mathrm{w} \backslash \mathrm{o})$ emulsion solvent evaporation technique and subsequently evaluated for its different physical parameters as well as its in vitro and in vivo drug release study. Results. The formulations F2 (98.42) and F3 (98.03) showed a constant and high release in the dissolution profile, so among these two formulations, F2 was taken for development study, due to the better result shown over in other evaluation parameters. From the HPLC determinations after in vivo study, it had been found that the test samples and the standard sample had not shown any significant fluctuation in relation to their retention time. Conclusion. From in vitro and in vivo results, it may be concluded that drug-loaded pectin microspheres in $1: 1$ ratio are a suitable delivery system for metformin hydrochloride and may be used for effective management of NIDDM. From this experiment, it could be concluded that as a natural polymer, pectin has potentiality in novel drug delivery system.
\end{abstract}

\section{Introduction}

novel system of drug delivery offers a means of improving the therapeutic effectiveness of incorporated drugs by providing sustained, controlled delivery and targeting the drug to desired site. A number of systems containing various types of polymer and wax were fabricated with drugs into dosage form with the aim of sustaining drug levels and hence drug action is obtained for an extended period of time [1]. However, a lack of understandings of anatomical and physiological barriers imposed impediment on the development of efficient delivery system. The modern era of controlled release technology represents the period in which an attempt at drug development is emphasized. The drug delivery system should deliver a drug at a rate dictated by the needs of the body over a specified period of treatment $[2]$.
Pectin was first isolated and described in 1825 by Henri Braconnot, though the action of pectin to make jams and marmalades was known long before. To obtain well-set jams from fruits that had little or only poor quality pectin, pectinrich fruits or their extracts were mixed into the recipe. During industrialization, the makers of fruit preserves soon turned to producers of apple juice to obtain dried apple pomace that was then cooked to extract pectin [3]. Naturally, pectin in the form of complex, insoluble protopectin is part of the nonwoody parts of terrestrial plants. In the middle lamella between plant cells, pectin helps to bind cells together and regulates water in the plant. These are methylated ester of polygalacturonic acid and it is commercially extracted from citrus peels and apple pomace under mild acidic conditions [4].

Metformin $\mathrm{HCl}(\mathrm{MFH})$ is indicated for patients with noninsulin-dependent diabetes mellitus (NIDDM), particularly those with refractory obesity [5]. 


\section{Materials and Method}

MFH was a kind gift from Zydus Health care (Sikkim, India). Pectin was purchased from Loba Chemie (Mumbai, India). HPMC was purchased from Loba Chemie (Mumbai, India). Ethyl cellulose and Acrycoat S100 were purchased from Sd Fine-chemicals (Mumbai, India) and Corel Pharma (Ahmedabad, India), respectively. All other chemicals used in the study were of analytical grade.

\section{Methodology}

3.1. $w \backslash$ o Emulsion Solvent Evaporation Method [6]. Microspheres were prepared by the water in oil $(\mathrm{w} \backslash \mathrm{o})$ emulsion solvent evaporation technique. The drug is dissolved in polymeric aqueous solutions. The solution was poured into $200 \mathrm{~mL}$ of paraffin liquid containing $0.5 \%$ span 80 as an emulsifying agent. The aqueous phase was emulsified into the oily phase by stirring the system in a $500 \mathrm{~mL}$ beaker and its content was heated by a hot plate at $80^{\circ} \mathrm{C}$. Stirring and heating was maintained for $2.5 \mathrm{hr}$ till the aqueous phase was completely removed by evaporation. The light oil was decanted and collected microsphere washed three times with $10 \mathrm{~mL}$ hexane, filtered through whatmann filter paper, dried in an oven for $2 \mathrm{~h}$, and stored in desiccators at room temperature.

Formulation F1-F8 was prepared by using drug with different ratios of pectin $(1: .5,1: 1,1: 1.5,1: 2$, and $1: 2.5,1: 3$, $1: 3.5$, and $1: 4$ ) and formulation F9-F12 was prepared by using drug with different polymers in same ratio $(1: 1)$ for further development.

3.2. Percentage Yield [7]. The yield was calculated as the weight of the microspheres recovered from each batch divided by total weight of drug and polymer total amount of that particular batch multiply by 100 .

3.3. Drug Content Estimation and Drug Entrapment Study [8]. The loaded microspheres $(100 \mathrm{mg})$ were powdered and suspended in $100 \mathrm{~mL}$ methanolic water $(1: 99 \mathrm{v} \backslash \mathrm{v})$ as a solvent. The resultant dispersion was kept for 20 mins for complete mixing with continuous agitation and filtered through a $0.45 \mu \mathrm{m}$ membrane filter. The drug content was determined spectrophotometrically (UV-1700, Shimadzu, Japan) at $233 \mathrm{~nm}$ using a regression equation from the standard graph.

The drug entrapment efficiency was calculated by the equation

$$
\mathrm{DEE}=\left(\frac{\mathrm{Pc}}{\mathrm{Tc}}\right) \times 100
$$

Here, Pc is the practical content, Tc is the theoretical content, and all the experimental unites were analyzed in triplicate.

3.4. Percent of Moisture Loss [8]. The MFH loaded microspheres of different polymers were evaluated for percentage of moisture loss which shares an idea about its hydrophilic nature. The microspheres weighed initially and kept in a desiccators containing calcium chloride at $37^{\circ} \mathrm{C}$ for 24 hours. The final weight was noted when no further change in weight of sample.

3.5. Determination of Size Distribution of Microspheres [9]. The microspheres were sized and photographed in normal saline containing $0.1 \%$ Tween 80 to prevent aggregation under a light microscope (Olympus C 011, Japan) equipped with an ocular micrometer and a light camera (Seagull DF-1, China). Two hundred microspheres were sized by the abovementioned method and the mean diameter as well as size distribution of microspheres were determined.

3.6. Morphological Study Using Scanning Electron Microscopy (SEM) [10]. The microspheres are studied under photomicroscope RXL-5T (Carton Optical Industries Ltd, Burdwan University, West Bengal, India) and observed for the distribution of drug and polymer in the patches. The surface morphologies of the microspheres were investigated by using scanning electron microscope, samples were gold coated to make them electrically conductive.

\subsection{Drug Polymer Interaction Study}

3.7.1. Fourier Transform Infrared Radiation Measurement (FT-IR) [11]. The FTIR spectral measurements were taken at ambient temperature using IR spectrophotometer (Shimadzu, model 840, Japan). Two mg of pure drug, empty microspheres, and drug-loaded microspheres were selected separately.

3.7.2. In Vitro Drug Release [12]. In vitro drug release study was carried out in USP XXI basket-type dissolution test apparatus using $6.8 \mathrm{pH}$ phosphate buffers as a dissolution medium. Volume of dissolution medium was $900 \mathrm{~mL}$. Bath temperature was maintained at $37 \pm 1^{\circ} \mathrm{C}$ throughout the study. Basket speed was adjusted to $50 \mathrm{rpm}$. Samples were withdrawn ( $5 \mathrm{~mL}$ ) in $5 \mathrm{~min}, 10 \mathrm{~min}, 15 \mathrm{~min}, 20 \mathrm{~min}, 30 \mathrm{~min}$, $45 \mathrm{~min}, 60 \mathrm{~min}$, and then an interval of $1 \mathrm{~h}$. up to $9 \mathrm{~h}$ with replacement of $5 \mathrm{~mL}$ fresh medium and analyzed for $\mathrm{MFH}$ content by UV-visible spectrophotometer at $233 \mathrm{~nm}$. All the experimental units were analyzed in triplicate $(n=3)$. The in vitro dissolution data is summarized in Figure 3, for F1 to F8. All the formulations found to release MFH in a controlled manner.

In order to study the exact mechanism of drug release [13] from microspheres, drug release data was analyzed according to zero order, first order [14], and Higuchi's square root $[14,15]$. The criterion for selecting the most appropriate model was chosen on the basis of goodness of fit test.

3.7.3. Statistical Analysis [8, 16]. All the results obtained during evaluation were verified with different statistical analyses like one-way ANOVA, standard deviation, and probability log scale plotting (for measurement of particle size). 


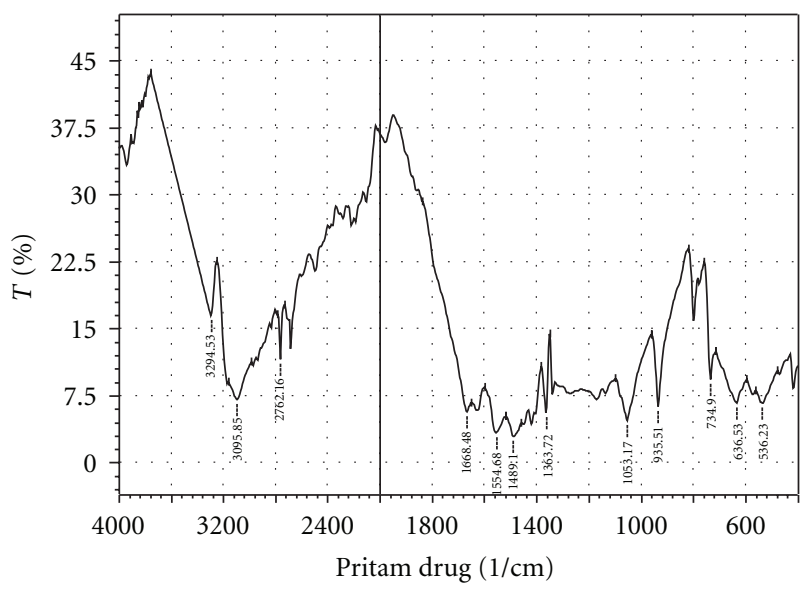

FIgURE 1: FT-IR spectrum of Metformin $\mathrm{HCl}$.

3.7.4. In Vivo Evaluation [17, 18]. Rabbits (New Zealand, white) of either sex weighing $(2.8-3.2 \mathrm{Kg})$ are divided into four groups, each consisting of six animals. First group was taken as diabetic control, second group received placebo, third group received an oral dose of $(25 \mathrm{mg})$ pure metformin hydrochloride, and third group received an oral dose of $25 \mathrm{mg}$ formulated drug.

Group 1: Diabetic control,

Group 2: Placebo,

Group 3: Diabetic rats treated with $25 \mathrm{mg} / \mathrm{kg}$ metformin $\mathrm{HCl}$ pure drug,

Group 4: Diabetic rats treated with $25 \mathrm{mg} / \mathrm{kg}$ of pectin microsphere,

The drugs are put behind the tongue to avoid their destruction due to biting. Food was withdrawn from the rabbits $12 \mathrm{hrs}$ before drug administration. All rabbits had free access to water throughout the study. The institutional Animal Ethical Committee approved the protocol for this study.

Blood samples were collected from the marginal ear vein of rabbits at $0,1,3$, and 5 hrs, respectively. Blood samples are centrifuged at $2000 \mathrm{rpm}$ for $10 \mathrm{mins}$ (Remi Equipment, Mumbai, India) and drug concentration after deproteinization with mobile phase was determined by HPLC assay (Shimadzu, Kyoto Corporation, Japan). Result was shown in Table 6.

3.7.5. Procedure for Separation of Plasma [19]. Firstly, $10 \mathrm{~mL}$ iodine-free saline solution and $1 \mathrm{~mL}$ of heparin were taken into a beaker to wash the syringe properly. Then blood samples were taken from the marginal ear vein of the rabbits. The blood sample was then subjected to cooling centrifuge along with 5\% TCA solution (anticoagulating agent). The cooling centrifuge was operated for $10 \mathrm{~min}$ and then it was passed through the column of silica gel to absorb the impurities.

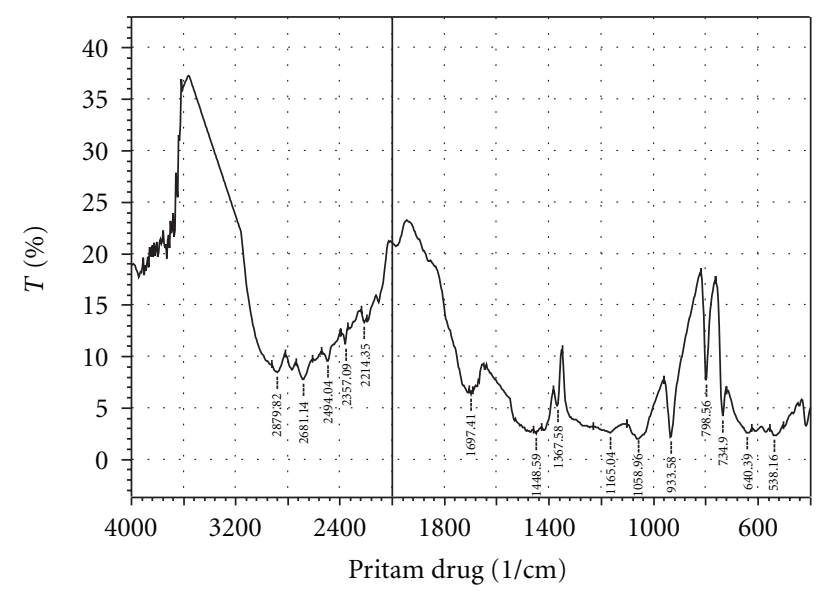

Figure 2: FT-IR spectrum of pectin with Metformin $\mathrm{HCl}$.

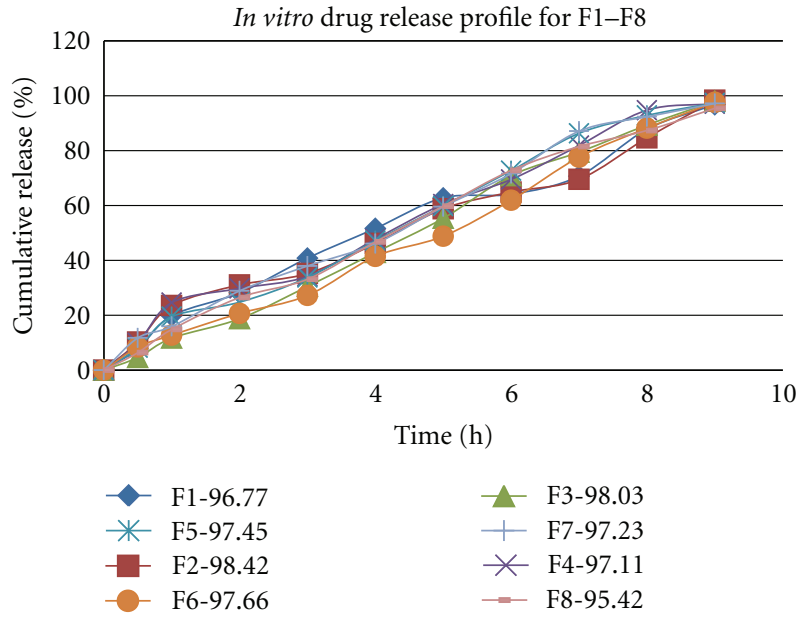

Figure 3: Comparative cumulative amount of MFH released from microsphere prepared by pectin in different ratios.

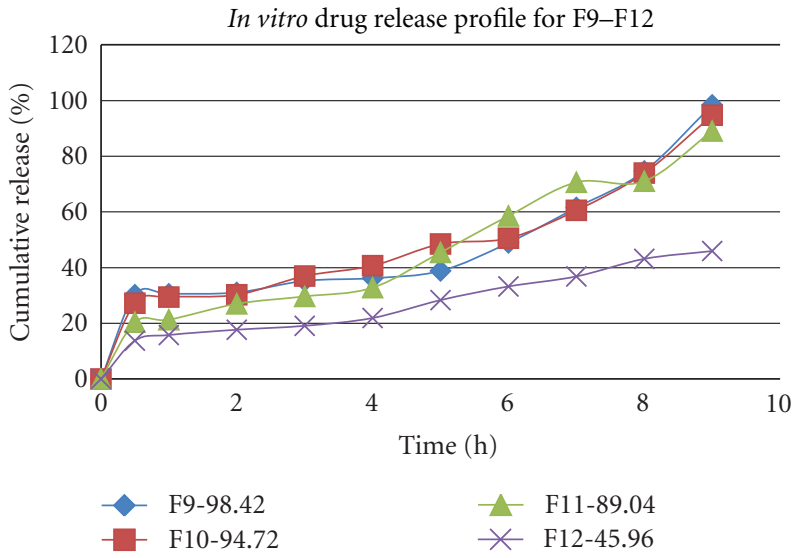

Figure 4: Comparative cumulative amount of MFH released from microsphere prepared by pectin (F9), ethyl cellulose (F10), HPMC (F11), and Acrycoat $\mathrm{S} 100$ (F12) in same (1:1) ratio. 
TABLE 1: Formulation development design.

\begin{tabular}{|c|c|c|c|}
\hline Formulation & Drug: polymer & Polymers used & Method of preparation \\
\hline F9 & $1: 1$ & Pectin & $\mathrm{W} \backslash \mathrm{O}$ emulsion solvent evaporation \\
\hline F10 & $1: 1$ & Ethyl cellulose & Solvent evaporation \\
\hline F11 & $1: 1$ & HPMC & Solvent evaporation \\
\hline F12 & $1: 1$ & Acrycoat S100 & Solvent evaporation \\
\hline
\end{tabular}

TABle 2: Physicochemical parameters of microspheres.

\begin{tabular}{lcccccc}
\hline Formulation & $\begin{array}{c}\text { Yield }(\%) \\
(\mathrm{X} \pm \mathrm{SD})\end{array}$ & $\begin{array}{c}\text { Actual drug } \\
\text { content }(\mathrm{mg}) \\
(\mathrm{X} \pm \mathrm{SD})\end{array}$ & $\begin{array}{c}\text { Theoretical drug } \\
\text { content }(\mathrm{mg})\end{array}$ & $\begin{array}{c}\text { Drug entrapment } \\
\text { efficiency }(\%) \\
(\mathrm{X} \pm \mathrm{SD})\end{array}$ & $\begin{array}{c}\text { Particle size } \\
(\mu \mathrm{m})\end{array}$ & $\begin{array}{c}\text { Moisture loss }(\%) \\
(\mathrm{X} \pm \mathrm{SD})\end{array}$ \\
\hline F1 & $85.2 \pm .098$ & $17.98 \pm .116$ & 66.66 & $26.97 \pm .167$ & $34.56 \pm .213$ & 1.07 \\
F2 & $84.00 \pm .078$ & $33.67 \pm .014$ & 50.02 & $67.34 \pm .178$ & $38.43 \pm .265$ & 2.25 \\
F3 & $81.76 \pm .105$ & $22.43 \pm .018$ & 40.21 & $55.78 \pm .161$ & $58.59 \pm 178$ & 1.13 \\
F4 & $84.8 \pm .142$ & $17.79 \pm .011$ & 33.33 & $53.37 \pm .132$ & $49.67 \pm .189$ & 1.22 \\
F5 & $78.8 \pm .112$ & $13.81 \pm .078$ & 28.57 & $48.33 \pm .096$ & $83.66 \pm .208$ & 1.49 \\
F6 & $84.8 \pm .069$ & $18.27 \pm .063$ & 28.21 & $64.76 \pm .189$ & $56.64 \pm .228$ & $69.22 \pm .256$ \\
F7 & $88.08 \pm .117$ & $15.37 \pm .035$ & 25.22 & $60.94 \pm .154$ & 608 & 1.43 \\
F8 & $86.68 \pm .098$ & $15.69 \pm .021$ & 26.07 & $60.18 \pm .089$ & $71.34 \pm .159$ & $34.56 \pm .213$ \\
F9 & $84.00 \pm .078$ & $39.67 \pm .014$ & 50.02 & $67.34 \pm .178$ & $39.04 \pm .194$ \\
F10 & $86.90 \pm .035$ & $20.80 \pm .032$ & 50.00 & $41.60 \pm .153$ & 39 \\
F11 & $76.10 \pm .161$ & $14.91 \pm .063$ & 51.09 & $29.82 \pm .119$ & $42.31 \pm .231$ & 0.89 \\
F12 & $80.50 \pm .073$ & $16.34 \pm .124$ & 50.00 & $32.68 \pm .096$ & $48.21 \pm .176$ \\
\hline
\end{tabular}

Value represent mean $\pm \mathrm{SD}(n=3)$.

TABLE 3: In vitro drug release kinetics.

\begin{tabular}{lccc}
\hline $\begin{array}{l}\text { Serial number } \\
\text { Formulation code }\end{array}$ & Zero order & $\begin{array}{c}r^{2} \text { value } \\
\text { First order }\end{array}$ & Higuchi \\
\hline F9 & $\mathbf{0 . 9 2 6}$ & 0.769 & 0.942 \\
F10 & $\mathbf{0 . 9 4 6}$ & 0.761 & 0.856 \\
F11 & $\mathbf{0 . 9 4 7}$ & 0.912 & 0.931 \\
F12 & $\mathbf{0 . 9 7 3}$ & 0.949 & 0.927 \\
\hline
\end{tabular}

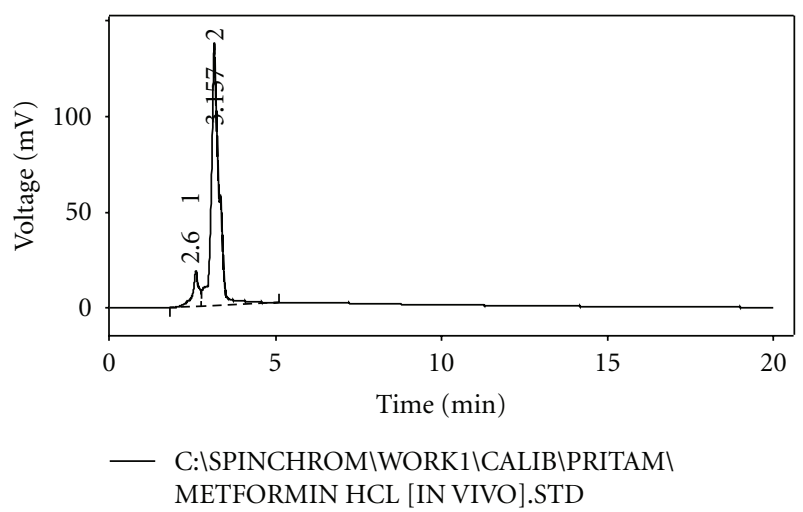

FIGURE 5: HPLC chromatogram of pure metformin hydrochloride.

3.7.6. HPLC Assay [20]. The determination of drug in plasma was performed by HPLC assay using methanol and phosphate buffers, $\mathrm{pH} 4.3(75: 25 \mathrm{vol} \backslash$ vol $)$ mixtures as

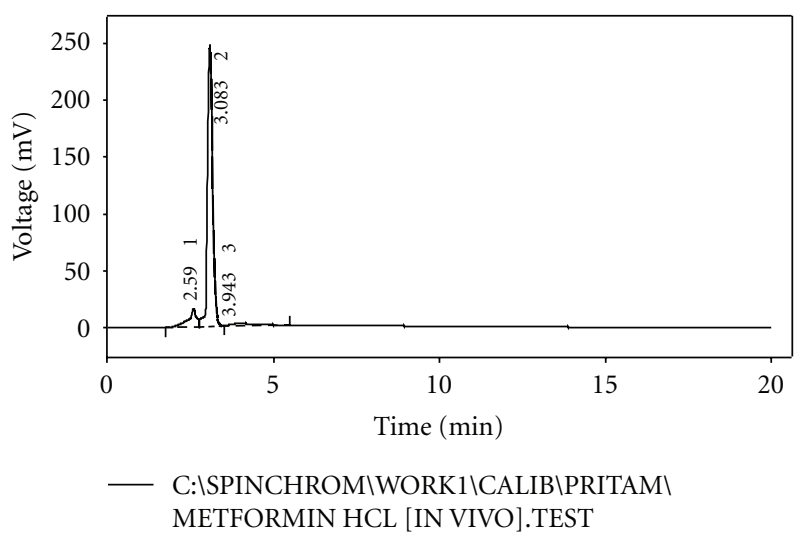

Figure 6: HPLC chromatogram of formulated sample (F9).

mobile phase delivered at a rate of $1.0 \mathrm{~mL} \backslash \mathrm{min}$ by HPLC pump (LC-20 AT) and the detector (SPD-20A). Twenty microliters of injected volume was eluted in column at room temperature. The column eluent was monitored at $236 \mathrm{~nm}$.

\section{Results and Discussion}

$\mathrm{w} \backslash \mathrm{o}$ emulsion solvent evaporation technique was used to prepare the microsphere of MFH using different polymers. Formulations F1-F8 were prepared by using drug with different ratios of pectin $(1: .5,1: 1,1: 1.5,1: 2,1: 2.5,1: 3$, $1: 3.5$, and $1: 4)$ and formulations F9-F12 were prepared 
TABLE 4: Effect of pectin microspheres of metformin $\mathrm{HCl}$ on alloxan induced diabetic rats.

\begin{tabular}{|c|c|c|c|c|c|c|}
\hline \multirow{2}{*}{ Serial number } & \multirow{2}{*}{ Design of control } & \multirow{2}{*}{ Drug } & \multicolumn{4}{|c|}{ Blood glucose level mg/dL } \\
\hline & & & $0 \mathrm{hr}$ & $1 \mathrm{hr}$ & $3 \mathrm{hr}$ & $5 \mathrm{hr}$ \\
\hline 1 & Diabetic control & - & $304.7 \pm 5.2$ & $312.3 \pm 1.4$ & $301.8 \pm 3.5$ & $318.2 \pm 7.1$ \\
\hline 2 & Placebo & - & $101.2 \pm 9.6$ & $134.7 \pm 7.1$ & $137.7 \pm 5.8$ & $131.9 \pm 5.8$ \\
\hline 3 & Pure metformin $\mathrm{HCl}$ & $25 \mathrm{mg} / \mathrm{kg}$ & $298.7 \pm 6.4$ & $134.4 \pm 5.3^{*}$ & $156.2 \pm 7.8^{*}$ & $205.3 \pm 7.8^{*}$ \\
\hline 4 & Pectin microsphere & $25 \mathrm{mg} / \mathrm{kg}$ & $297.5 \pm 13.6$ & $206.1 \pm 4.3^{*}$ & $192.5 \pm 5.4^{*}$ & $173.1 \pm 9.3^{*}$ \\
\hline
\end{tabular}

$N=6,{ }^{*} P<0.001$ versus control, values are expressed as mean \pm SEM. ${ }^{*}$ Statistically significant when compared with diabetic controls $(P<0.05)$.

TABLE 5: HPLC observation of standard sample.

\begin{tabular}{lcccccc}
\hline Serial number & Retention time $(\mathrm{min})$ & Area $(\mathrm{mV} \cdot \mathrm{s})$ & Height $(\mathrm{mV})$ & Area $(\%)$ & Height $(\%)$ & WO5 $(\mathrm{min})$ \\
\hline 1 & 2.600 & 252.728 & 18.832 & 10.2 & 12.1 & 0.18 \\
2 & 3.157 & 2236.742 & 137.046 & 89.8 & 87.9 & 0.20 \\
\hline & Total & 2489.470 & 155.877 & 100.0 & 100.0
\end{tabular}

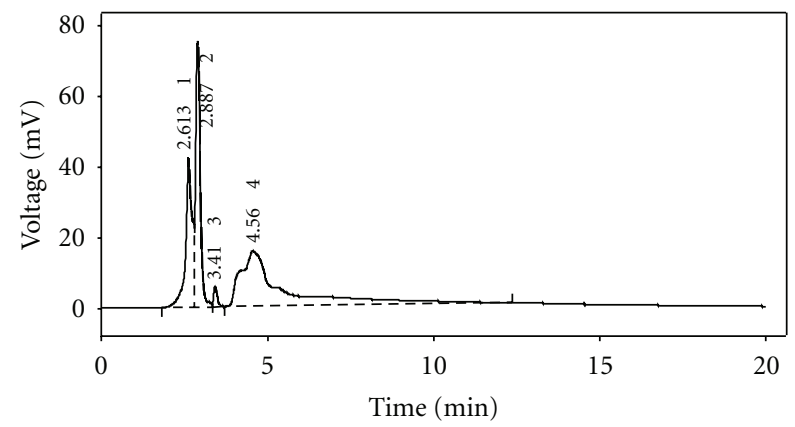

- C:ISPINCHROM $\backslash W O R K 1 \backslash C A L I B \backslash P R I T A M \backslash$ METFORMIN HCL [IN VIVO] BLANK

FIGURE 7: HPLC chromatogram of blank sample.
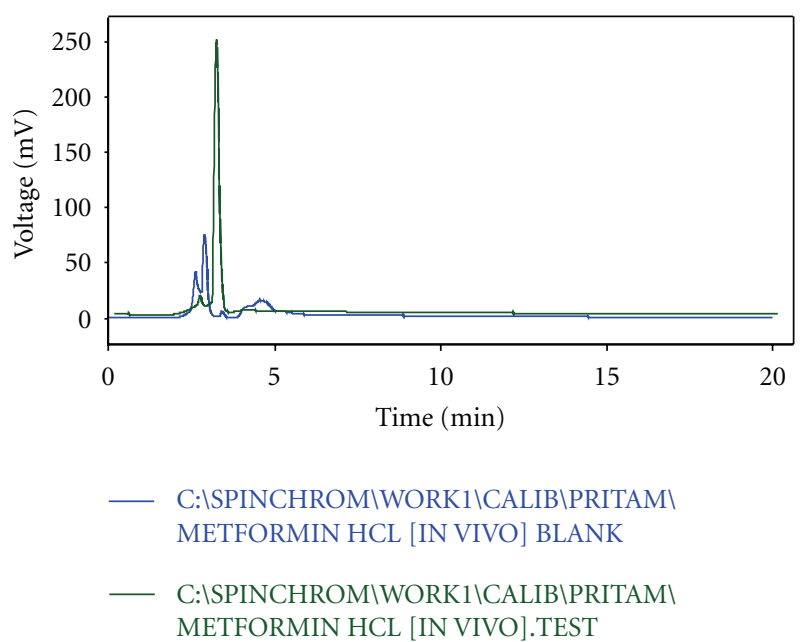

FIGURE 8: Overlap of HPLC chromatogram between blank and test.

by using drug with different polymers in the same ratio (1:1) for development study which was shown in Table 1. Evaluation of all formulations like percentage yield, drug content estimation, drug entrapment, percentage of moisture loss, size distribution, morphological study by scanning

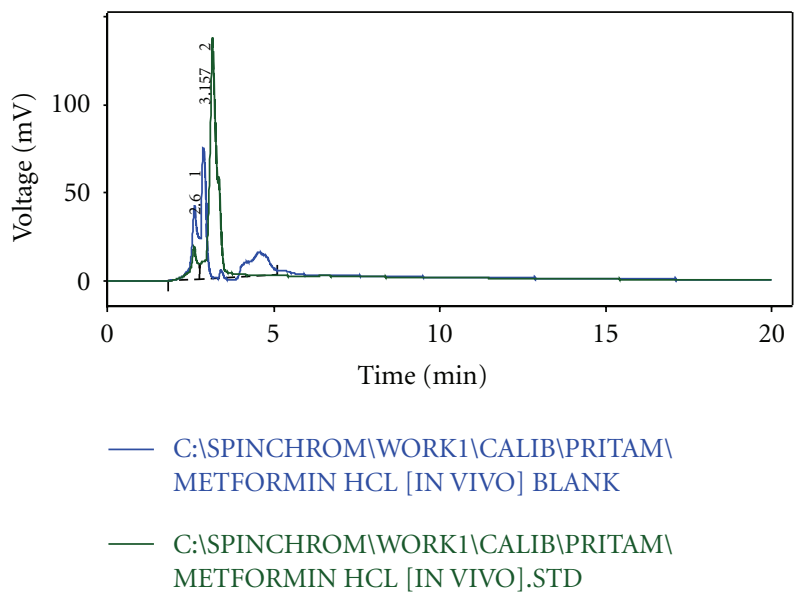

FIGURE 9: Overlap of HPLC chromatogram between blank and standard.

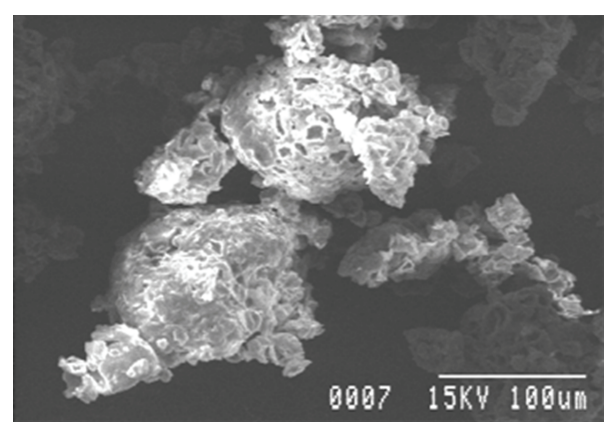

Figure 10: SEM photograph of microspheres (Magnification $\times 100)$.

electron microscopy (SEM), drug polymer interaction, in vitro drug release, and in vivo studies were done accordingly. The percentage yield of all the formulations was found to be satisfactory as shown in Table 2. It can be due to the involvement of process parameters. Drug entrapment efficiency (DEE) of F2 formulation found to be high 
TABLE 6: HPLC observation of test sample with standard.

\begin{tabular}{lcccccc}
\hline Serial number & Retention time $(\mathrm{min})$ & Area $(\mathrm{mV} \cdot \mathrm{s})$ & Height $(\mathrm{mV})$ & Area $(\%)$ & Height $(\%)$ & WO5 $(\mathrm{min})$ \\
\hline 01 & 2.590 & 302.087 & 16.545 & 9.9 & 6.2 & 0.19 \\
02 & 3.083 & 2609.617 & 247.284 & 85.5 & 92.8 & 0.16 \\
03 & 3.943 & 142.206 & 2.523 & 4.7 & 0.9 & 1.37 \\
\hline & Total & 3053.911 & 266.352 & 100.0 & 100.0 & \\
\hline
\end{tabular}

Retention time of test: $2.590 \mathrm{~min}$; retention time of standard: $2.600 \mathrm{~min}$.

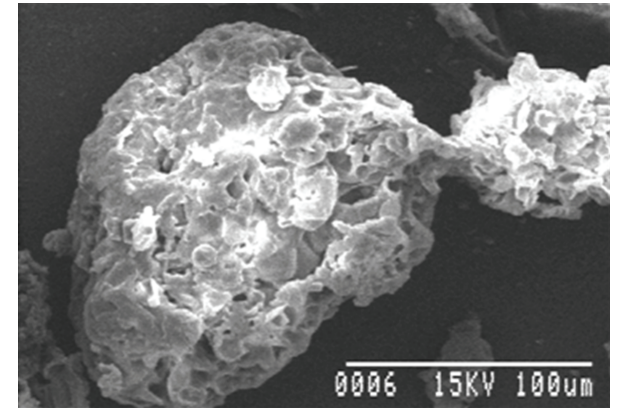

Figure 11: SEM photograph of microspheres (Magnification $\times 500)$.

because the drug is fully dispersed in the polymer phase by continuous stirring for a period of 5-6 hrs. Very less amount of moisture was loss after 24 hrs except F3, indicating negligible presence of water in all the formulations as shown in Table 2. Table 2 showed the particle size of all the formulations found to be satisfactory and within the range of $(34.56$ to $83.66 \mu \mathrm{m})$. This narrow range of particle size can be attributed as the effect of stirring time and stirring speed during preparation of microspheres. The microspheres obtained under these conditions were mostly spherical and without aggregation. To detect the surface morphology of microspheres, scanning electron microphotographs (SEM) study at different magnifications were done as shown in Figure 10 at $100 \mathrm{x}$ and Figure 11 at 500x, respectively.

From the infrared spectra $[21,22]$ Figures 1 and 2, it is clearly evident that there were no interactions of the drug with the polymer. The main peak in the spectrum of the drug metformin hydrochloride, both free and with polymer, does not show any substantial difference. The IR spectra show a peak at 1688.48 , which signifies the presence of $\mathrm{C}=\mathrm{N}$ (stretch) functional group. At 1254.14, a peak is observed which signifies the presence of C-N stretching. At 1473.34 wave numbers, a peak is also observed which signifies the presence of $\mathrm{C}-\mathrm{H}$ (bend in plane). Simultaneously, a peak at 732.97 wave numbers signifies the presence of $\mathrm{N}-\mathrm{H}$ (rocking) functional group. All the peaks were observed at the finger print region of the FT-IR spectra. This proves the fact that there is no potential incompatibility of the drug with the polymer (pectin) used in the formulations. Hence, the formula for preparing metformin hydrochloride microsphere with pectin can be reproducing in an industrial scale without any apprehension of possible drug-polymer interactions. After UV scanning, it was found that at $233 \mathrm{~nm}$ the drug-polymer solution give the highest absorbance which is similar to the absorbance given by the pure drug at UV region.

The formulations F2 and F3 show a constant and high release in the dissolution profile, so among from these two, F2 was taken for development study, due to its better result compared in other evaluation parameter. For further development of pectin microsphere, F9-F12 formulations were prepared by using different polymers in the same ratio $(1: 1)$ by solvent evaporation method. In case of pectin formulation (F9), the drug release was $98.42 \%$ up to 9 hrs. Comparatively at the same ratio ethyl cellulose (F10) given 94.72\%, HPMC (F11) given 89.04\% and Acrycoat S100 (F12) given 45.96\% up to $9 \mathrm{hrs}$, respectively. So we can conclude that natural pectin gives better controlled release compared to other polymer. The in vitro drug release data were summarized in Figure 3 for F1-F8 and Figure 4 for F9-F12, respectively. All the formulations considered for development were found to release $\mathrm{MFH}$ in a controlled manner. To describe the kinetics of drug release from microspheres, release data was analyzed according to different kinetic equations described in text in Table 3. Release data of F9, F10, F11, and F12 obeys zero order kinetic as well as Higuchi's square root equations. The formulation F9 prepared by $\mathrm{w} \backslash \mathrm{o}$ emulsion solvent evaporation method was found the release maximum in phosphate buffer $\mathrm{pH}$ 6.8. Putting all the data in different release kinetic models and comparing the coefficient of regression $\left(r^{2}\right)$, it was found that F9, F11, and F12 tend to fit with the Fickian diffusion model given by Higuchi confirming drug release by diffusion mechanism, whereas F9, F10, F11 and F12 fits with zero order kinetic model.

From the HPLC determinations, it has been found that the test samples and the standard sample do not show any significant fluctuation in relation to their retention time (Figures 5, 6, 7, 8, and 9). Thus, it can be inferred that the test sample (F9) showed significant release and presence of drug within the plasma (Tables 5 and 6). In the microspheretreated rat, the blood glucose level was steadily decreased from 1 st to $5 \mathrm{hr}$ and it was 206.1 to 297.5. It was concluded that the effect of antidiabetic activity of microspheres was in sustained action. Values are expressed as mean \pm SEM and statistically significant when compared with diabetic controls $(P<0.05)$ (Table 4).

\section{Conclusion}

The experimental design supported product development and development procedure yielded the desired microspheres with drug release for extended period of time. The polymer combination of Pectin, Ethyl Cellulose, HPMC and 
Acrycoat S-100 as release retardant, resulted, microspheres with good yield and moderate entrapment. The optimized pectin microsphere of $\mathrm{MFH}$ is expected to provide the clinicians with a new choice of an economical, safe and more bioavailable formulation in the management of type II diabetes mellitus. Therefore, it may be concluded that drug loaded pectin microspheres will be a suitable delivery system for metformin hydrochloride, and may be used for effective management of NIDDM.

Pectin was found to be a suitable alternative of semi synthetic polymers, which can be further employed in an industrial scale as an efficient release retardant in the formulation of microspheres.

\section{Acknowledgments}

The authors thank Zydus Health Care (Sikkim, India) for the generous gift of metformin hydrochloride. They also thank Department of Pharmaceutics, Himalayan Pharmacy Institute, Majhitar, East Sikkim, Sikkim, India, for providing infrastructure facilities for the research work.

\section{References}

[1] J. M. Gwen and J. R. Robinson, "Sustained and controlled release drug delivery systems," in Modern Pharmaceutics, vol. 72, p. 575, Marcel Dekker, New York, NY, USA, 3rd edition, 1996.

[2] W. Y. Thomas and J. R. Robinson, "Controlled release drug delivery system," in The Science and Practice of Pharmacy, vol. 1, p. 903 , 20th edition, 2001.

[3] P. Sriamornsak, "Chemistry of pectin and its pharmaceutical uses : a review," Silpakorn University International Journal, vol. 3, no. 1-2, pp. 206-228, 2003.

[4] L. S. Liu, Y. J. Won, P. H. Cooke et al., "Pectin/poly(lactideco-glycolide) composite matrices for biomedical applications," Biomaterials, vol. 25, no. 16, pp. 3201-3210, 2004.

[5] P. K. Choudhury and M. Kar, "Controlled release metformin hydrochloride microspheres of ethyl cellulose prepared by different methods and study on the polymer affected parameters," Journal of Microencapsulation, vol. 26, no. 1, pp. 46-53, 2009.

[6] A. Semalty and M. Semalty, "Preparation and characterization of mucoadhesive microspheres of ciprofloxacin hydrochloride," in Controlled Release Polymeric Formulations, pp. 345351, American Chemical Society, 1993.

[7] K. N. Shovarni and A. G. Goundalkar, "Preparation and evaluation of microsphere of diclofenac sodium," Indian Journal of Pharmaceutical Sciences, vol. 56, no. 2, pp. 45-50, 1994.

[8] P. K. Rout and B. S. Nayak, "Formulation design, preparation of losartan potassium microspheres by solvent evaporation method and it's in vitro characterization," Archives of Pharmaceutical Sciences and Research, vol. 1, no. 1, pp. 166-170, 2009.

[9] M. C. Gohel, R. K. Parikh, and A. Surati, "Preparation and formulation evaluation of diclofenac sodium," Indian Journal of Pharmaceutical Sciences, vol. 67, no. 5, pp. 575-581, 2005.

[10] D. R. Bhumkar and M. M. Patil, "Studies on effect of variabilities by response methodology for naproxane microspheres," Indian Drugs, vol. 40, no. 8, pp. 455-461, 2003.
[11] K. Abu-Izza, L. Garcia-Contreras, and D. R. Lu, "Preparation and evaluation of zidovudine-loaded sustained-release microspheres. 2. Optimization of multiple response variables," Journal of Pharmaceutical Sciences, vol. 85, no. 6, pp. 572-576, 1996.

[12] J. Wang and D. R. Flanagan, "General solution for diffusioncontrolled dissolution of spherical particles. 1. Theory," Journal of Pharmaceutical Sciences, vol. 88, no. 7, pp. 731-738, 1999.

[13] D. M. Morkhade, S. V. Fulzele, P. M. Satturwar, and S. B. Joshi, "Gum copal and gum damar: Novel matrix forming materials for sustained drug delivery," Indian Journal of Pharmaceutical Sciences, vol. 68, no. 1, pp. 53-58, 2006.

[14] T. Higuchi, "Mechanism of sustained-action medication. Theoretical analysis of rate of release of solid drugs dispersed in solid matrices," Journal of Pharmaceutical Sciences, vol. 52, no. 12, pp. 1145-1149, 1963.

[15] H. Fesssi, J.-P. Marty, F. Puisieux, and J. T. Carstensen, “The Higuchi square root equation applied to matrices with high content of soluble drug substance," International Journal of Pharmaceutics, vol. 1, no. 5, pp. 265-274, 1978.

[16] S. Bolton, "Analylisis of varience," in Pharmaceutical StatisticsPractical and Clinical Application, pp. 235-269, Marcel Dekker, New York, NY, USA, 1997.

[17] K. Rajagopal and K. Sasikala, "Antihyperglycaemic and antihyperlipidaemic effects of Nymphaea stellata in alloxan-induced diabetic rats," Singapore Medical Journal, vol. 49, no. 2, pp. 137-141, 2008.

[18] P. Daisy and M. Rajathi, "Hypoglycemic effects of Clitoria ternatea Linn. (Fabaceae) in alloxan-induced diabetes in rats," Tropical Journal of Pharmaceutical Research, vol. 8, no. 5, pp. 393-398, 2009.

[19] R. L. Thies, D. W. Cowens, P. R. Cullis, M. B. Bally, and L. D. Mayer, "Method for rapid separation of liposome-associated doxorubicin from free doxorubicin in plasma," Analytical Biochemistry, vol. 188, no. 1, pp. 65-71, 1990.

[20] D. Jain, S. Jain, D. Jain, and M. Amin, "Simultaneous estimation of metformin hydrochloride, pioglitazone hydrochloride, and glimepiride by RP-HPLC in tablet formulation," Journal of Chromatographic Science, vol. 46, no. 6, pp. 501-504, 2008.

[21] G. R. Chatwal and S. K. Anand, "Infrared absorption spectroscopy," in Instrumental Methods of Chemical Analysis, pp. 2.29-2.82, Himalayan Publishing House, Mumbai, India, 5th edition, 2005.

[22] W. Kemp, "Infrared spectroscopy," in Organic Spectroscopy, pp. 19-99, ELBS with Macmillan, Hong Kong, China, 3rd edition, 1996. 

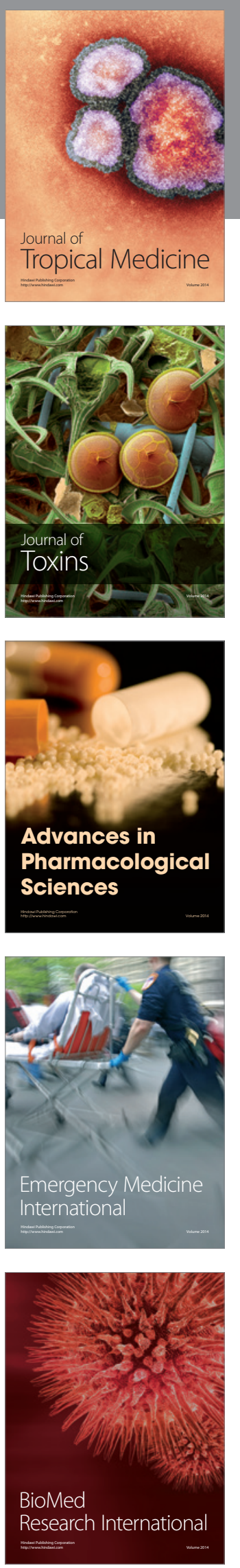
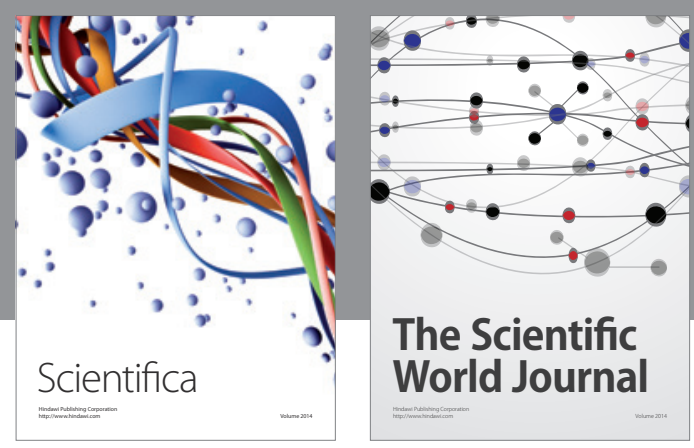

The Scientific World Journal
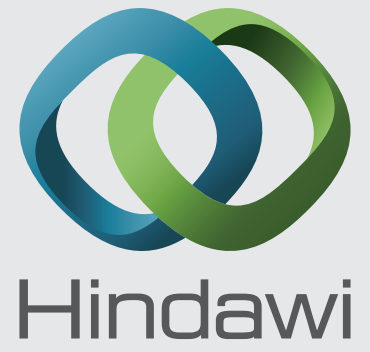

Submit your manuscripts at

http://www.hindawi.com
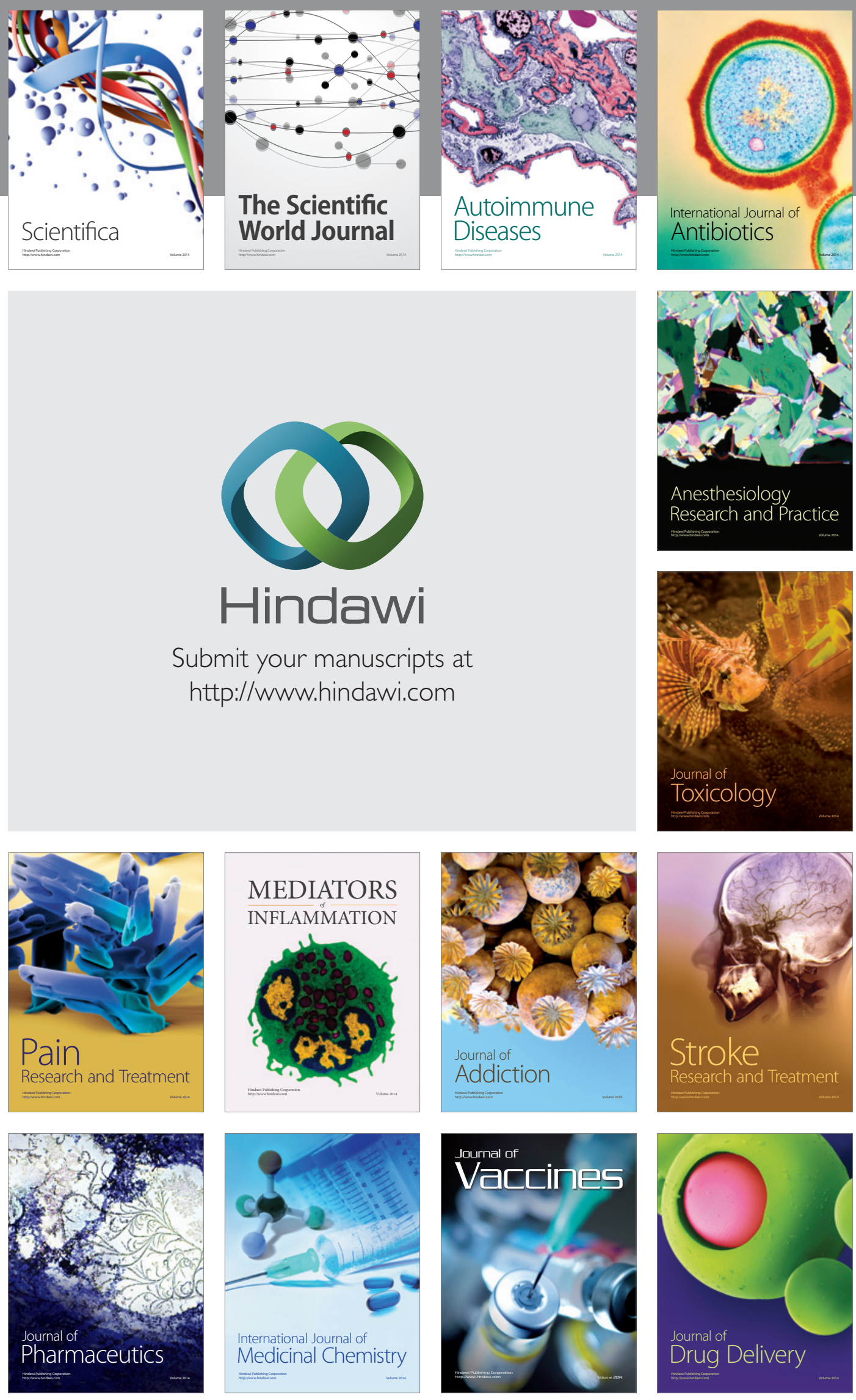